\title{
RENOMBRAMIENTO DE CALLES EN CONTEXTOS BÉLICOS: CANARIAS DURANTE LA GUERRA CIVIL ESPAÑOLA (1936-1939)
}

\author{
STREETS RENAMING IN WAR CONTEXTS: THE CANARY ISLANDS \\ DURING THE SPANISH CIVIL WAR (1936-1939)
}

\author{
Néstor García Lázaro* (iD y Aarón León Álvarez** (i)
}

Fecha de Recepción: 27 de mayo de 2020

Fecha de Aceptación: 25 de septiembre de 2020

\begin{abstract}
Cómo citar este artículo/Citation: Néstor García Lázaro, Aarón León Álvarez (2021). Renombramiento de calles en contextos bélicos: Canarias durante la Guerra Civil Española (1936-1939). Anuario de Estudios Atlánticos; nº 67: 067-017.

http://anuariosatlanticos.casadecolon.com/index.php/aea/article/view/10588/10167

ISSN 2386-5571. https://doi.org/10.36980/10588.10167
\end{abstract}

Resumen: El objetivo de este artículo es analizar el renombramiento de las calles que se produjo en España durante la Guerra Civil en un territorio de retaguardia, Canarias. Para ello, se han trabajado las actas de las comisiones gestoras y la prensa del período. Desde el marco teórico de los critical placename studies analizamos la evolución diacrónica, las nuevas denominaciones y los espacios que ocupan en el entramado urbano, así como las instituciones y personas involucradas en el proceso. Con ello, abordamos un aspecto de la construcción simbólica de la dictadura de Franco, vinculada con la religión y el ejército.

Palabras clave: Guerra Civil, franquismo, estudios toponímicos, toponimia, nombres de calles.

\begin{abstract}
The objective of this article is the analysis of street renaming during the Spanish Civil War in a rearguard territory, the Canary Islands. For this, we considered the Management Commissions' minutes and the press of that time. Within the theoretical framework of critical place-name studies we analyze the diachronic evolution, the new denominations, the occupied spaces in the urban network, as well as the institutions and people involved in the renaming process. We aim to address the symbolic construction taken place during Franco's Dictatorship, and its link to religion and the army.
\end{abstract}

Keywords: Spanish Civil War, Franco's Dictatorship, critical place-name studies, place names, street names.

\section{INTRODUCCIÓN}

Los letreros de las calles, que se nos muestran como cotidianos y banales, cumplen una función administrativa y política de control sobre la población y el espacio público ${ }^{1}$. Esta última cuestión se ve reforzada en los nombres de las vías con fines conmemorativos, que son un elemento común en la cultura política moderna. La autoridad encargada de este acto administrativo fundamenta el orden sociopolítico imperante y su particular teoría del mundo en el paisaje urbano ${ }^{2}$. Con ello, la ideología del régimen político es experimentada por la población

\footnotetext{
${ }^{*}$ Doctor en Historia por la Universidad de Las Palmas de Gran Canaria. Centro de Estudios y Difusión del

Atlántico (CEDA). Las Palmas de Gran Canaria. España. Correo electrónico: garcialazaro.nestor@gmail.com

${ }^{* *}$ Doctor en Historia por la Universidad de La Laguna. Funcionario de carrera (docente). Consejería de Educación, Universidades, Cultura y Deportes. Gobierno de Canarias. Avda. Buenos Aires, 5. Edificio Tres de Mayo, 38071. Santa Cruz de Tenerife. España. Correo electrónico: aaronleoalv@gmail.com

1 AZARYAHU (2012), p. 461.

2 AZARYAHU (1996), pp. 311-312; DROZDZEWSKI (2014), p. 68.
} 
como obvia y familiar. Así, los nombres conmemorativos de las calles transforman el discurso oficial en una experiencia cultural compartida que se inserta en las prácticas de la vida cotidiana $^{3}$.

Debido a la función política e ideológica de los nombres de las calles, cuando se produce un cambio de régimen las nuevas autoridades proceden, entre otras acciones, a renombrar aquellas que poseen alguna vinculación con el régimen depuesto. Así, según Maoz Azaryahu, se consigue la deconmemoración de la versión de la historia asociada y apoyada por la antigua forma de gobierno, mientras que por otro lado se conmemoran los héroes y eventos que representan al nuevo régimen ${ }^{4}$, De esta manera, se introduce el cambio político y su ideología en la vida cotidiana de la población. Es un poderoso mensaje del control del nuevo régimen sobre la infraestructura simbólica de la comunidad ${ }^{5}$, una celebración del triunfo, así como una reestructuración de las relaciones de poder y una reconstrucción de las instituciones sociales y políticas. En fin, un acto de propaganda política ${ }^{6}$.

A partir de julio de 1936 esta situación determinaría aquellos territorios de España que pasaron a estar controlados por los sublevados: territorios de retaguardia en los que se empezó a configurar un nuevo marco político y normativo y en los que, entre otras cosas, se inició un proceso de reconfiguración simbólica. Canarias fue uno de esos lugares.

El objetivo de este trabajo es analizar la política cultural del (re)nombramiento de las calles de las islas durante la Guerra Civil. Al mismo tiempo, nos proponemos conocer la evolución diacrónica de este proceso y los nombres otorgados durante el período, haciendo referencia a la evolución cronológica y de denominación de esas calles, así como a otras cuestiones relacionadas con la gestión política de este proceso.

Tal y como queda recogido en los libros de actas de las sesiones de las comisiones gestoras de los Ayuntamientos durante el período 1936-1939 — marco temporal de este artículo—, así como en la prensa de la época, se produjo un proceso de resignificación del espacio público que supondría, entre otras cosas, el cambio del nombre de algunas calles. En total, estudiamos detalladamente la nomenclatura de las calles y plazas de 35 de los 90 municipios que existían en Canarias durante el período de 1936 a 1939, es decir, casi el 40\% del total. Hemos incluido las dos capitales provinciales (Santa Cruz de Tenerife y Las Palmas), las cinco capitales insulares restantes y las ciudades más pobladas y de mayor peso económico de Canarias en esos momentos. Al mismo tiempo, analizamos contextos rurales con escasa población, de manera que se puede ver el impacto de este proceso más allá de los principales núcleos de las islas e incorporamos espacios poblacionales más reducidos, menos poblados, eminentemente agrícolas y con un escaso desarrollo viario para explicar el proceso de manera más detallada y representativa. De modo que aportamos una visión global de Canarias $\mathrm{y}$, al mismo tiempo, tratamos de hacer representativo los diferentes espacios poblaciones locales, siguiendo otras propuestas desarrolladas para diferentes trabajos en Europa ${ }^{7}$.

Este estudio lo planteamos desde la etimología y taxonomía, parámetros de los critical place-name studies, que en las últimas décadas han reformulado el foco tradicional de la toponimia, para centrarse en la política de las prácticas de la designación de lugares ${ }^{8}$. En concreto, tomamos como referencia las líneas de investigación de Reuben Rose-Redwood, Derek Alderman y Maoz Azaryahu, en tanto que han abordado cómo las personas buscan controlar, negociar y contestar el proceso de nombrar las calles, vinculado con las luchas más amplias por su legitimidad y visibilidad en las que participan ${ }^{9}$.

Las investigaciones que se han desarrollado en los últimos años siguiendo el giro crítico en el estudio de los nombres de los lugares ${ }^{10}$ han prestado una gran importancia a las políticas de renombramiento de las calles en los períodos de cambio de régimen político. La mayoría de

3 ROSE-REDWOOD, ALDERMAN y AZARYAHU (2010), p. 459.

4 AZARYAHU (2011a), pp. 483-492.

5 ROSE-REDWOOD, ALDERMAN y AZARYAHU (2010), p. 460.

6 AZARYAHU (1996), p. 318.

7 AZARYAHU (2011b), p. 29.

8 ROSE-REDWOOD, ALDERMAN y AZARYAHU (2010), pp. 453-470

9 ROSE-REDWOOD, ALDERMAN y AZARYAHU (2010), p. 457.

10 ROSE-REDWOOD, ALDERMAN y AZARYAHU (2010). 
estos trabajos se han centrado en países que han transitado de una dictadura a una democracia, como por ejemplo los países poscomunistas ${ }^{11}$ y los contextos poscoloniales de África y Asia ${ }^{12}$. Una característica de estos contextos políticos es que la posibilidad de volver a la situación previa era prácticamente imposible. Por su parte, son escasos los trabajos que han estudiado las políticas de renombramientos de las calles en contextos dictatoriales ${ }^{13}$.

La historiografía española sobre el franquismo ha prestado cierta atención al tema durante los últimos años. En general, se ha analizado el renombramiento de calles como un resultado del cambio de régimen político y que vendría caracterizado por el interés por dominar el espacio público con símbolos para moldearlo, a partir de la creación de emociones colectivas y la aceptación de un espacio común. En conjunto, este proceso contribuiría a crear y consolidar una parcialidad en torno a una determinada concepción nacional ${ }^{14}$. De igual forma, se ha explicado en estudios sobre la memoria de la dictadura y su deseo de pervivir, a la par que se relacionan con asentar su legitimidad y convertir el poder en autoridad ${ }^{15}$. En otros casos, sobre todo en estudios de carácter local, se plantea una relación general del cambio de nombres y el proceso histórico analizado ${ }^{16}$. Si nos ceñimos al planteamiento que proponemos para este artículo, contamos con algunas publicaciones que se han acercado a los renombramientos de las calles desde la óptica de la memoria histórica ${ }^{17}$. También existen otros trabajos generales que no se limitan exclusivamente a la guerra o al franquismo y que tratan de identificar orígenes y continuidades en ese proceso ${ }^{18}$.

En el caso concreto del archipiélago, los estudios sobre el tema son prácticamente inexistentes y suelen limitarse a menciones generales en libros de historia local. En efecto, se suelen realizar relaciones de los cambios de calles indicando la fecha y las denominaciones que se cambiaban y las que se introducían. De modo que se detecta una ausencia de análisis y explicación que vaya más allá de esa cuestión y que evidencia un considerable vacío historiográfico para el estudio del período ${ }^{19}$.

\section{CALLES PARA UN NUEVO RÉGIMEN}

El proceso de cambio de un régimen político suele llevar aparejado, con mayor o menor intensidad, transformaciones en ámbitos diversos. Uno de ellos se vincula directamente con el

11 Véanse, entre otros, los trabajos de AZARYAHU (1997) y MARIN (2012).

12 Algunas referencias que hay que tener en cuenta son las de BIGON y NJOH (2015), DUMINY (2014) y WANJIRU y MATSUBARA (2017).

13 Cabe destacar en este sentido los trabajos de DROZDZEWSKI (2014) y AZARYAHU (1986).

14 BOX (2010), p. 285. En su caso, además plantea una investigación en la que un proceso que se inicia a partir de la victoria en la guerra y la mitificación que conllevará la exaltación de los caídos y de sus lugares de memoria, al tiempo que todo iría enlazado con los símbolos (bandera, himno...) y un calendario conmemorativo (18 de julio, 12 de octubre, etc.).

15 BOX (2010), p. 19. Véanse también AGUILAR FERNÁNDEZ, Paloma (2008) y GODICHEAU, F. y ARÓSTEGUI, J. (2006). Hay que tener en cuenta aportaciones concretas como las de Santos Juliá, Xosé Manuel Núñez-Seixas, Laura Zenobi o Francisco Sevillano Calero en torno a la idea de cultura de guerra, el sentido nacionalista de la acción de los sublevados y la construcción del mito de Franco y de los caídos.

16 Existe una relación considerable de trabajos que han abordado esta cuestión en el territorio peninsular desde la década de los ochenta y hasta la actualidad (San Sebastián, Bilbao, Salamanca, Granada, Logroño, Vigo, Alicante, etc.).

17 CASTRO (2008), pp. 213-224; RINA (2012), pp. 35-55; RINA (2013), pp. 444-462; LÓPEZ DE MATURANA (2014), pp. 76-83; HENALES (2019), pp. 111-130.

18 De esa manera, se habla de calles como "crónicas vivientes" en las que se desarrollan las experiencias de la ciudadanía, de modo que leer los letreros de esas calles es hojear un pasado presente. SUBIRANA (2017), p. 71. En este sentido, también puede verse la relación que se establece entre conciencia histórica y cultura histórica en SÁNCHEZ (2009), pp. 232-235.

19 Disponemos de alguna aproximación inicial al tema, atendiendo al proceso de recatolización y de reconstrucción simbólica del espacio público durante la guerra civil en LEÓN (2016), pp. 73-83. También disponemos de un estudio sobre el etiquetado de calles en los municipios tinerfeños de Santa Cruz y La Laguna durante la dictadura y el posterior proceso de transición a la democracia en GARCÍA (2011), pp. 281-308. Precisamente en este trabajo se citan varias obras recopilatorias sobre el cambio de calles a las que nos referíamos más arriba para la provincia de Santa Cruz de Tenerife. Para el caso de Las Palmas, en cambio, se pueden mencionar otros trabajos de interés como los de NAVARRO (1940 y 1943) y PLATERO (1998). 
espectro simbólico, el cual se manifiesta habitualmente y con notable intensidad en el espacio público. En concreto, se pueden producir situaciones de renombramiento de las vías de comunicación, algo que debe entenderse como una prerrogativa y una expresión de poder de las autoridades ${ }^{20}$, que, como veremos, se manifestará directamente en las decisiones de las comisiones gestoras de los ayuntamientos.

Durante el verano de 1936 fueron pocas las comisiones gestoras que adoptaron acuerdos relacionados con el (re)nombramiento de las calles de sus municipios (cuadro 1). En la provincia de Las Palmas lo hicieron cinco comisiones, mientras que en la de Santa Cruz de Tenerife tan sólo dos, entre ellas las dos capitales provinciales canarias. Sin embargo, los primeros cambios se produjeron en municipios rurales como Güímar (12 de agosto de 1936), en la provincia de Santa Cruz de Tenerife, y Moya (28 de agosto de 1936), en la de Las Palmas.

El proceso de modificación del nombre de las calles vendría marcado por las órdenes de la Comandancia Militar de Canarias que fueron comunicadas a los ayuntamientos por parte de los dos gobernadores civiles de las islas. Según disponía el comandante militar, debido a que se vislumbraba la culminación del «resurgir de España sobre sus legendarias bases y valores», había llegado el momento de «rectificar los nombres y designaciones de calles, plazas, etc.» con el fin de desterrar «lejos de nosotros cuantos representan nombres, símbolos de ideas que en totalidad rechazamos los verdaderos patriotas, sustituyéndolos por los tradicionales o bien aquellos nuevos que respondan al verdadero y hondo sentir del país» ${ }^{21}$. De esta manera, la política de «memoria franquista» que se estaba construyendo durante la guerra perseguía un fin: «la legitimación del propio régimen, el anclaje del mismo como consecuencia casi lógica de la evolución en la tradición de la gloriosa historia española, y a la vez tenía que liquidar el recuerdo de la parte contraria» ${ }^{22}$.

Como se puede observar en el cuadro 1, a partir de octubre de 1936 y hasta final de ese mismo año, se produjo el mayor número de acuerdos relacionados con la eliminación de los nombres vigentes durante la segunda República, el régimen anterior. Aquello que Azaryahu, tal y como ya hemos mencionado más arriba, definió como la deconmemoración. Este proceso se concentró sobre todo en la provincia de Santa Cruz de Tenerife, con 20 acuerdos en ese sentido en 17 de los 21 municipios estudiados. Esas decisiones fueron adoptadas, en la mayoría de los casos, a partir de la comunicación del gobernador civil de la provincia, lo cual indicaría que no hubo un proceso de toma de decisiones directo por parte de las gestoras y que, al mismo tiempo, se logró centralizar y controlar en los primeros meses después del golpe de Estado. En ese sentido, igualmente importante es que esas modificaciones en el callejero se produjeron durante la guerra, en un momento en el que no estaba asegurada la victoria. Este hecho es sintomático del proceso de construcción de la dictadura que se estaba dando en el territorio de retaguardia canario desde un primer momento y de la necesidad de definir un nuevo espacio político y social que respondiera a los principios que parecían marcar los designios de la Nueva España.

$\mathrm{Si}$ atendemos a la cronología de esos cambios, cuando había transcurrido medio año desde que triunfara el golpe de Estado en las islas, se habían tomado en los municipios estudiados de Canarias casi el 60\% de los acuerdos adoptados durante el período 1936-1939 para nombrar las calles, siguiendo las pautas de las autoridades militares y civiles. En la provincia de Las Palmas fue un proceso continuado en el tiempo. En general, la diacronía de los cambios atendió a distintos aspectos, como la realización de estudios sosegados en las capitales provinciales sobre qué calles renombrar o la inclusión de calles que, en los primeros momentos, se habían pasado por alto, pero eran necesarias eliminar por su vinculación con el socialismo o el republicanismo o por los fallecimientos durante la guerra de personajes ilustres del bando sublevado a los que era necesario recordar con una calle en sus poblaciones.

Hasta ese momento, las órdenes habían venido de parte de las autoridades militares y civiles de ámbito regional y provincial. Sin embargo, el proceso sería dirigido a partir de 1938 por una agencia estatal, cuestión frecuente en muchos Estados, debido a la importancia que estos

20 AZARYAHU (2011a), pp. 483-484.

21 «Circular del Gobierno Civil de Las Palmas» (26 de septiembre de 1936). Boletín Oficial de la Provincia de Las Palmas, suplemento al núm. 116, 28 de septiembre de 1936. En el caso de la provincia occidental se recogerá la circular de 23 de septiembre en las actas municipales.

22 BERNECKER y BRINKMANN (2009), p. 131. 
nombres tienen en la construcción de una identidad nacional ${ }^{23}$. El 13 de abril de 1938 el Ministerio del Interior emanó una orden en Burgos con la que pretendía centralizar este proceso de cambio y evitar que se produjeran «actuaciones censurables». Según lo que se recoge en ella, esas acciones podrían ir contra la historia, la tradición, la cultura y «la convivencia del vecindario casi siempre». Lo cierto es que en municipios como Teguise (Lanzarote) y Fasnia (Tenerife) se renombraron las plazas principales del municipio con el nombre del general Franco en 1938, al que se había concedido una plaza menos relevante en $1936^{24}$. Por otro lado, durante este período, en municipios como Firgas (Gran Canaria), además de eliminar la nomenclatura de las vías aprobada durante la segunda República, se cambiaron nombres tradicionales como norte, sur, nueva o capellanía ${ }^{25}$. Aspectos a los que se hacía alusión en la orden como inconvenientes. A partir de su publicación, las comisiones gestoras tenían que realizar una consulta previa al Servicio Nacional de Administración local, dependiente del Ministerio del Interior, para eliminar «los casos de evidente agravio para los principios inspiradores del Movimiento Nacional». Para honrar la memoria «de hombres ilustres» y «de hechos laudables», se aconsejaba servirse de las nuevas calles o de las afectadas por las supresiones excepcionales ${ }^{26}$. No obstante, no se produjo ningún cambio por parte de las comisiones gestoras de la provincia de Santa Cruz de Tenerife ${ }^{27}$. mientras que en las de la otra provincia canaria se produjo una serie de cambios durante 1938 y 1939 (véase cuadro 1).

\begin{tabular}{|l|c|c|c|}
\hline Año & $\begin{array}{c}\text { Provincia de Las } \\
\text { Palmas }\end{array}$ & $\begin{array}{c}\text { Provincia de Santa } \\
\text { Cruz de Tenerife }\end{array}$ & Canarias \\
\hline Julio-septiembre 1936 & 6 & 4 & 10 \\
\hline Octubre-diciembre 1936 & 8 & 20 & 28 \\
\hline Enero-marzo 1937 & 2 & 2 & 4 \\
\hline Abril-junio1937 & 6 & 1 & 5 \\
\hline Julio-septiembre 1937 & 3 & 2 & 3 \\
\hline Octubre-diciembre 1937 & 1 & 1 & 2 \\
\hline Enero-marzo 1938 & 1 & 1 & 3 \\
\hline Abril-junio 1938 & 2 & 0 & 0 \\
\hline Julio-septiembre 1938 & 0 & 0 & 1 \\
\hline Octubre-diciembre 1938 & 1 & 0 & 0 \\
\hline Enero-marzo 1939 & 0 & 0 & 1 \\
\hline Abril-junio 1939 & 1 & 0 & 1 \\
\hline Julio-septiembre 1939 & 1 & 33 & 65 \\
\hline Total & 32 & & \\
\hline
\end{tabular}

Cuadro 1. Evolución diacrónica de los acuerdos adoptados por las comisiones gestoras sobre el cambio de los nombres de las calles y plazas de sus municipios.

Elaboración propia. Fuentes: Archivos municipales citados y referencias bibliográficas.

La situación canaria en el contexto de la Guerra Civil difiere respecto a la de distintas ciudades en contextos posdictatoriales y poscoloniales, donde se determina el cambio de los nombres de las calles en la primera reunión de los gobiernos municipales ${ }^{28}$. Debido a la inexistencia de estudios en Canarias, desconocemos si los cambios se inscriben en las tradiciones municipales sobre el cambio de los nombres de los lugares durante los cambios de régimen acaecidos durante los siglos XIX y XX, o si tenemos que vincular lo observado durante el período de estudio con un contexto bélico, en el que existía la posibilidad de volver al

23 COHEN y KLIOT (1992), p. 661; AZARYAHU (1996), pp. 313-314; AZARYAHU (1997), p. 481.

24 Archivo Histórico Municipal de Teguise: «Libro de actas de las sesiones celebradas por la Corporación Municipal del Ayuntamiento de la Villa de Teguise. Año 1936» (Teguise, 26 de marzo de 1938), ff. 95 vto. - 96 r.; RODRÍGUEZ (2 de junio de 2015).

25 Archivo Histórico Provincial de Las Palmas (en adelante AHPLP). Ayuntamiento de Firgas: «Libro de actas de Firgas. Año 1935» (Firgas, 5 de octubre de 1936), f. 93.

26 «Orden del Ministerio del Interior» (13 de abril de 1938). Boletín Oficial del Estado, núm. 540, 14 de abril de 1938 .

27 Véanse los casos de Burgos y Cáceres. CASTRO (2008), pp. 219-220; RINA (2012), pp. 46-47.

28 AZARYAHU (2011a), pp. 483-484; GRABAR (2014), p. 399. 
régimen que se intentaba deponer. De todos modos, lo que ocurre en este territorio insular de retaguardia también distó mucho de la inmediatez descrita por Jesús de Andrés para los territorios tomados por los militares sublevados durante la Guerra Civil en la península ibérica ${ }^{29}$.

Desde que se adoptaban los acuerdos en las comisiones gestoras sobre (re)nombramiento de las vías de sus municipios hasta que se fijaban los nuevos nombres en el espacio público solía transcurrir un promedio de seis meses. Este período aumentaba de forma considerable en las dos capitales provinciales. En la ciudad de Las Palmas se produjo el primer acuerdo para renombrar las calles de la ciudad el 9 de septiembre de $1936^{30}$. Transcurrido un mes, uno de los gestores realizó un ruego para que se diera cumplimiento al acuerdo sobre rotulación de calles. Desde la presidencia se le respondió que se estaban realizando los trabajos encaminados a tal fin. Debido a la situación bélica, no era posible traer desde Barcelona las placas para la rotulación de las nuevas calles ${ }^{31}$, desde donde parece ser que el Ayuntamiento de Las Palmas solía hacer sus encargos antes del golpe de Estado ${ }^{32}$. Esta puede ser la causa que explique la tardanza en otras localidades.

Otra de las causas que puede explicar la demora a la hora de señalar la nueva denominación de esas calles es la situación económica de los municipios ${ }^{33}$. No debemos olvidar que el elevado coste que suponía la adquisición de nuevas placas hizo que en ciudades como Berlín los cambios efectivos fueran menores a los propuestos ${ }^{34}$, y que en la Timisoara poscomunista muchos de sus habitantes fueran contrarios a los nuevos nombres de las calles por el coste que llevaba aparejado el proyecto $^{35}$. En este sentido, el mismo gestor de la Comisión Gestora de Las Palmas, en noviembre de 1936, propone que cuando los «recursos del Ayuntamiento lo permitan» deberían de sustituirse las chapas de metal o mármol por «ladrillos de nuestras típicas cerámicas» ${ }^{36}$. Más allá de que los «ladrillos-letra», tal y como se conocían, pudieran tener un elemento identitario vinculado con la tradición, habría que valorar que la propuesta tenía como objetivo solucionar el problema de tener las calles sin letreros con sus nuevos nombres, es decir, sin un significado propiamente dicho. Esta situación se dilató, como mínimo, hasta finales de julio de 1937 en que por parte de la Comisión Gestora se aprobó una propuesta de la Comisión de Policía Urbana, según la cual se ordenó, con toda urgencia, la colocación de los «rótulos en las calles cuyos nombres han sido modificados ${ }^{37}$. Por su parte, en la ciudad de Santa Cruz de Tenerife, el 6 de diciembre de 1937 después de realizar el renombramiento de una serie de calles, la Comisión Gestora aprueba «que seguidamente se proceda a la rotulación de estas vías y de todas las demás a que se haya cambiado el nombre después del Glorioso Movimiento Nacional» ${ }^{38}$.

No hay constancia documental de si durante este período de tiempo, que superó el año, las calles se encontraban con letreros que hacían mención a las denominaciones suprimidas a partir del golpe de Estado o si, por el contrario, se encontraban desprovistas de cualquier tipo de placa

29 ANDRÉS (2006), pp. 8-9.

30 AHPLP, Ayuntamiento de Las Palmas de Gran Canaria: «Libro de actas $n^{\circ} 94$ del Pleno Municipal, fechas 26/08/1936 - 24/11/1937» (Las Palmas, 9 de septiembre de 1936), ff. 11 vto. - 12 r.

31 AHPLP, Ayuntamiento de Las Palmas de Gran Canaria: «Libro de actas $n^{\circ} 94$ del Pleno Municipal, fechas 26/08/1936 - 24/11/1937» (Las Palmas, 14 de octubre de 1936), f. 35 r.

32 Hasta el momento solo conocemos talleres de marmolistas hasta 1915, por lo que desconocemos la existencia de talleres locales en Canarias durante la década de 1930. Sobre los mismos léase RAMÍREZ (2016), pp. $62-72$.

33 En el caso de Firgas, se facultó al alcalde para que comprara las lápidas el 5 de octubre de 1936, que se recibieron en la primera quincena de febrero de 1937. Sin embargo, no se pagó a una persona para la colocación de las lápidas en las calles del pueblo hasta abril de 1937. AHPLP, Ayuntamiento de Firgas: «Libro de actas de Firgas. Año 1935» (Firgas, 5 de octubre de 1935); Véase «Libro de actas del Ayuntamiento pleno. Trece de noviembre de 1936 al catorce de junio de 1940» (Firgas, 15 de febrero de 1937 y 15 de abril de 1937).

34 AZARYAHU (2011a), pp. 488-490.

35 GRETAN y MATTHEWS (2016), pp. 92-102.

36 AHPLP, Ayuntamiento de Las Palmas de Gran Canaria: «Libro de actas $n^{\circ} 94$ del Pleno Municipal, fechas 26/08/1936 - 24/11/1937» (Las Palmas, 11 de noviembre de 1936), f. 52 r.

37 AHPLP, Ayuntamiento de Las Palmas de Gran Canaria: «Libro de actas n 94 del Pleno Municipal, fechas 26/08/1936 - 24/11/1937» (Las Palmas, 28 de julio de 1937), f. 186 vto.

38 Archivo Municipal de Santa Cruz de Tenerife: «Libro de actas $n^{\circ} 32$ del Ayuntamiento de Santa Cruz de Tenerife» (Santa Cruz de Tenerife, 6 de diciembre de 1937). 
indicativa del nombre de la vía. Esta situación asociada al renombramiento de las calles tuvo su efecto en la experiencia humana y en la cognición del espacio. Como afirma Maoz Azaryahu, se tuvo que producir una disonancia cognitiva y un desorden mental y de comunicación entre la gente común por esta ruda intervención en el hábitat y las prácticas cotidianas ${ }^{39}$.

Lo cierto es que estos cambios no solo afectaron a la gente común, sino que también repercutió en la clase política local. Durante la Guerra Civil, los miembros de varias comisiones gestoras tuvieron que aclarar los nombres anteriores de las calles donde se pretendían acometer distintos tipos de obras ${ }^{40}$. Esta situación se prolongó en muchos municipios, como mínimo, hasta la década de 1940. En el caso del Ayuntamiento de San Mateo (Gran Canaria), se hacía mención a los nombres previos al cambio realizado en 1937, sin ninguna aclaración del nombre que poseía a partir de dicha fecha. Así ocurrió con calles con fechas tan señaladas como «18 de julio», a la que se seguía nombrando como calle Norte durante las sesiones del Ayuntamiento ${ }^{41}$. Un elemento que debemos conectar con los hábitos rutinarios y con la inercia, ya que los mismos son difíciles de romper, tal y como han planteado Duncan Light y Craigh Young para la persistencia del nombre de un mercado de la era socialista en la actual Bucarest ${ }^{42}$.

\section{NUEVA NOMENCLATURA Y UBICACIÓN DE LAS NUEVAS CALLES}

Durante la Guerra Civil en Canarias se produjo la construcción social del espacio común, con la representación de los símbolos del nuevo régimen político, con nuevas pautas y, como veremos más adelante, con la inclusión de todos los elementos centrales del discurso franquista a modo de autolegitimación.

En los municipios canarios estudiados se renombró un total de 220 calles y plazas desde el 18 de julio de 1936 hasta 1939. Para este ritual de la revolución, como lo ha definido Maoz Azaryahu $^{43}$, se utilizaron 97 nombres distintos para sustituir los vigentes durante el régimen anterior. Algo más del 70\% del total (71 nombres de calles) se encuentran presentes tan sólo en un único municipio, lo que demuestra la autonomía que tuvieron las comisiones gestoras en este proceso.

La selección de nombres que pasaron a formar parte de la nomenclatura de calles, siguiendo lo dispuesto por el comandante militar, se dividieron en dos grandes grupos: los que recuperaban las denominaciones tradicionales que habían sido suprimidas durante la segunda República y «aquellos nuevos que respondan al verdadero y hondo sentir del país» ${ }^{44}$, es decir, los que estuvieran en consonancia con la visión del mundo que tenía el nuevo régimen. Esto determinó que se construyera un viario público que, como se verá a continuación, se caracterizó por la recuperación de calles que recordaban a figuras del catolicismo y de la tradición local, al tiempo que incorporaban a personas que, aunque no tuvieran relación directa con las islas, en cambio, sí fueran determinantes para lo que sucedía en la política nacional. Era algo intencionado y que relacionaba a las personas con su entorno y con su adhesión al espacio, a la vez que contribuyó a la creación de una «memoria colectiva» a partir de un espacio que se puede sentir como propio en un momento dado ${ }^{45}$. Algo que paralelamente contribuye a una cohesión social que, en todo caso, partiría de la depuración y división social generada por la guerra y la represión franquista.

39 AZARYAHU (1996), p. 317.

40 AHPLP, Ayuntamiento de San Mateo: «Libro de actas del Ayuntamiento (1934 a 1938)» (San Mateo, 29 de septiembre de 1937), f. 153 r.; AHPLP, Ayuntamiento de Valleseco: «Actas de Pleno, 14 noviembre 1936 a 14 mayo 1939. Libro 84» (Valleseco, 28 de marzo de 1938), f. 53 r.

41 AHPLP, Ayuntamiento de San Mateo: «Libro de actas del Ayuntamiento, 1938 a 1943» (San Mateo, 12 de mayo de 1943), f. $140 \mathrm{r}$.

42 LIGHT y YOUNG (2014), pp. 679-683.

43 AZARYAHU (1997), p. 481-482.

44 «Circular del Gobierno Civil de Las Palmas» (26 de septiembre de 1936). Boletín Oficial de la Provincia de Las Palmas, suplemento al núm. 116, 28 de septiembre de 1936.

45 HALBWACHS (2002), p. 10. En este sentido, «las políticas de memoria del Franquismo, en especial las relacionadas con los símbolos, fueron políticas públicas fundamentales, encargadas de cubrir el déficit democrático de la Dictadura, de elaborar una nueva cultura política y una nueva memoria histórica, y de socializar políticamente a varias generaciones de españoles». ANDRÉS (2006), p. 34. 
En total se recuperaron 40 nombres tradicionales en 47 vías, lo cual representa casi el $22 \%$ del total de la muestra de estudio. Esto, que se puede considerar como un acto común en períodos de cambio político ${ }^{46}$, fue más notorio en la isla de Tenerife. Los nombres, por lo general, hacían alusión a elementos relacionados con la religión católica, aunque también existían otros vinculados con personajes históricos y denominaciones clásicas. Durante las sesiones en que se tomaban los acuerdos, los alcaldes defendían estas acciones argumentando que eran las denominaciones consagradas «por el pueblo y la costumbre» ${ }^{47}$. Al mismo tiempo que se recobraba el «pasado histórico que se intentó soterrar» por parte del régimen republicano ${ }^{48}$.

Habría que destacar que esa recuperación de la costumbre estaba unida habitualmente al santoral católico, donde predominaban los patronos locales. Una de las características de los nombres conmemorativos de las calles es la de introducir una versión autorizada de la historia en los entornos ordinarios de la vida cotidiana, así como una teoría del mundo, de acuerdo con el orden sociopolítico vigente ${ }^{49}$, tal y como hemos visto. En este caso, y como trataremos más adelante, hay que tener en cuenta que el personal político de esa primera etapa tendría una relación directa con la presencia de las elites conservadoras canarias y con el impacto que había tenido el quinquenio republicano en algunos municipios. Ese proceso sería predominante en aquellos lugares donde los republicanos y la izquierda tuvieron mayor influencia y lograron movilizar a mayor cantidad de personas. Como ejemplo, se puede citar el caso de La Orotava (Tenerife) donde, al igual que en el municipio vecino de Puerto de la Cruz, se produjo una intensa lucha entre campesinos y propietarios durante buena parte del período republicano y donde, a excepción de la denominación de la plaza principal como General Franco, el resto de cambios se tradujo en la sustitución de nombres como 14 de abril, Capitán García Hernández, Fermín Galán y Pablo Iglesias por sus nombres anteriores.

La mayor parte de las calles renombradas recibió un nombre nuevo a partir del golpe de Estado. Casi el $80 \%$, un total de 173 calles y plazas fueron bautizadas con 57 nombres que estaban en consonancia con la Nueva España (véase Cuadro 2).

El predominio de los nombres militares en las calles (45\% del total) conmemorativas debe relacionarse con el contexto bélico, así como con la propia naturaleza del régimen. El nombre de mayor relevancia en Canarias fue el del general Franco, que fue utilizado en 26 municipios de los estudiados para denominar plazas, calles, avenidas e incluso un muelle. En este sentido, se dio el caso de que en algunos municipios como Valverde (El Hierro) o San Bartolomé de Tirajana (Gran Canaria), fue el único cambio que se produjo en el nomenclátor de las vías de dichas poblaciones ${ }^{50}$.

La figura de Franco en las islas se había visto agrandada desde un primer momento por su breve paso por ellas en los meses previos al golpe de Estado, lo que coincidió además con el aumento de la conflictividad social y con la victoria del Frente Popular en las elecciones de febrero de 1936. Durante los años de la Guerra Civil y en adelante, desde la propaganda franquista en Canarias, se resaltaría continuamente que el nuevo Jefe de Estado había sido el comandante militar del archipiélago en aquellos años y que había partido desde allí a la península para iniciar la cruzada de liberación española. El Puerto de Las Palmas, desde donde partió hacia la Cruzada el 18 de julio, en el tercer aniversario de esta efeméride, se renombró como muelle del Generalísimo y se colocó «un sencillo monumento que recuerda la gloriosa

46 AZARYAHU (2011a), pp. 484-486; DROZDZEWSKI (2014), pp. 66-78; MARIN (2012), pp. 192-216.

47 Archivo Municipal de Güímar (en adelante AMG): «Libro de actas de 1936» (Güímar, 4 de noviembre de 1936), Libro 1728/2. No nos debe extrañar que los nombres recuperados por las comisiones gestoras fueran los utilizados por la propia población durante el régimen republicano, si tenemos en cuenta que el hábito ha hecho que muchos términos sigan usándose décadas después de haberse cambiado. Sobre ello léase LIGHT y YOUNG (2014), pp. 679-683.

48 AMG: «Libro de actas de 1936» (Güímar, 4 de noviembre de 1936), Libro 1728/2.

49 AZARYAHU (1996), pp. 311-312.

50 Archivo Municipal de Valverde: «Libro de actas de 18 de noviembre de 1934 a 2 de junio de 1940» (Valverde, 18 de octubre de 1936); AHPLP, Ayuntamiento de San Bartolomé de Tirajana: «Libro no 38 de las sesiones celebradas por el Ayuntamiento de San Bartolomé de Tirajana (1935-1940)» (San Bartolomé de Tirajana, 22 de septiembre de 1936). 
fecha y que será como un signo de gratitud de este pueblo hacia quien fue y es la garantía del engrandecimiento de la Patria» ${ }^{51}$.

Tal y como han puesto en evidencia los estudios sobre la toponimia crítica existe una estrecha vinculación entre las personalidades conmemoradas y la importancia de la vía en la que sus nombres se inscriben ${ }^{52}$. Derek H. Alderman ha llamado la atención sobre la importancia de la escala de la calle en relación con su tamaño y la relación de la misma con otras vías y lugares de la ciudad $^{53}$. En el caso de Canarias, nos encontramos con que las calles a las que se les cambiaban los nombres solían ser, no solo las más importantes por su ubicación, sino también, a veces, las pocas que podían considerarse como tales en municipios rurales, como eran mayoritariamente los canarios de aquella época. Si tenemos en cuenta esto, el impacto del (re)nombramiento de esas vías habría que valorarlo también en términos de concreción del nuevo dominio político e institucional y en referencia continua al orden imperante.

A partir de nuestro estudio, hemos identificado una jerarquización del propio espacio que confirma esa hipótesis de estudio de que las calles más destacadas, transitadas y que fueron referentes de las comunicaciones en cada municipio, iban a ser aquellas que se dedicarían a los hombres y símbolos de referencia del nuevo régimen ${ }^{54}$. En concreto, la figura de Franco sobresaldría sobre el resto, siendo su nombre el que identificara a las plazas y calles más destacadas de cada localidad. Además, incluso, en algunas de ellas, al recibir la denominación en homenaje al Caudillo, pasan a denominarse como avenidas o ramblas, perdiendo su antigua denominación de calle, y, por tanto, se engrandece su consideración ${ }^{55}$. En el caso de las plazas, fueron las principales del pueblo, algo que sucederá en otros contextos bélicos estudiados ${ }^{56}$.

De esta manera, se concretó en el espacio el liderazgo del general Franco en un contexto de guerra en el que su figura se identificaba con el heroísmo, la unidad y la eficacia de su figura ${ }^{57}$. En las islas, la mayoría de los acuerdos de las comisiones gestoras para denominar con su nombre las calles y plazas de los municipios se produjo inmediatamente después de que fuera nombrado jefe de Estado. De modo que, aunque se exaltaba su figura como comandante militar de Canarias y de haber partido desde ellas para la Península, el proceso de cambio se produjo cuando su figura tomó dimensión estatal y se convirtió en referente militar y jerárquico del proceso que estaba en marcha.

De manera puntual se incluyeron también algunos nombres/apellidos de altos mandos del Ejército en el callejero, como los de los generales Aranda, Balmes, Eulate, Orgaz o Yagüe. Frente a ellos, Queipo de Llano, Sanjurjo, Moscardó o Varela recibirían hasta cuatro denominaciones en las islas. En estas calles también se siguió la jerarquía militar, pues los generales tienen una mayor presencia: 16 personas que suelen estar en más de dos municipios. En el escalafón les siguen dos comandantes, cinco capitanes, dos tenientes y un cabo de infantería. Predominan los militares que jugaron un papel relevante en el golpe de Estado y durante la contienda bélica, aunque también hay que destacar la presencia de los militares vinculados con las islas desde la Comandancia Militar. El caso más importante lo tenemos en el

51 «Las Palmas celebra el III aniversario del Alzamiento» (18 de julio de 1939). Falange; AHPLP, Ayuntamiento de Las Palmas: «Libro de actas no 96 del Pleno Municipal», fechas 02/02/1939 - 25/01/1940 (Las Palmas, 30 de junio de 1939), f. 90 vto.

52 ALDERMAN y INWOOD (2013), pp. 211-233; DROZDZEWSKI (2014), p. 73; MEITAL (2007), p. 869; WANJIRU y MATSUBARA (2017), p. 5.

53 ALDERMAN (2003), pp. 163-173.

54 La céntrica vía comercial de Herradores en La Laguna (Tenerife) pasaría a homenajear a Francisco Franco en julio de 1937. También podrían citarse los casos de Teguise (Lanzarote) y Fasnia (Tenerife), pequeños municipios en los que en 1938 se renombraron las plazas principales del municipio con el nombre del general Franco, al que se le había concedido una plaza menos relevante en 1936. En este sentido, podría mencionarse el tratamiento que se le concedió al general Juan Yagüe en la ciudad de Burgos, donde estaba ligado por motivos personales y profesionales. CASTRO (2008), pp. 220-221.

55 En Canarias lo observamos, por ejemplo, en San Bartolomé de Tirajana, donde el 22 de septiembre de 1936 se aprobó el cambio de la calle dedicada a León y Castillo a favor de la Avenida del general Franco; caso similar se produciría en el municipio tinerfeño de Icod de Los Vinos donde la nueva avenida vendría a ocupar lo que hasta entonces se conocía como Vía del barranco Preceptor a los Pabellones Escolares Miguel Primo de Rivera.

56 Por ejemplo, la plaza principal de la ciudad polaca de Cracovia fue renombrada como Adolf Hitler durante la ocupación nazi. DROZDZEWSKI (2014), p. 73.

57 SEVILLANO (2017), p. 113 
general Dolla, que ocuparía el principal cargo militar en el archipiélago y que vería reconocida su figura solo en los municipios estudiados de la provincia de Santa Cruz de Tenerife. En el caso de los militares canarios, los menos, suelen ser personas fallecidas en el frente de batalla, como es el caso del Capitán Brotons, que recibe una calle en La Laguna, ciudad de la que era vecino; o héroes de guerra, como el laureado Antonio Alemán Ramírez, al que se le otorga una calle en la ciudad de Las Palmas, así como en la vía donde nació en el núcleo de Tenteniguada en el municipio de Valsequillo (Gran Canaria). En todos estos casos, se hacían breves menciones a su heroísmo y a su entrega para lograr el objetivo de la liberación de España ${ }^{58}$.

\begin{tabular}{|l|c|c|c|}
\hline Nombre de la calle & Provincia Las Palmas & $\begin{array}{c}\text { Provincia Santa Cruz } \\
\text { de Tenerife }\end{array}$ & $\begin{array}{c}\text { Totales en } \\
\text { Canarias }\end{array}$ \\
\hline General Franco & 10 & 16 & 26 \\
\hline José Antonio Primo de Rivera & 7 & 7 & 14 \\
\hline 18 de julio & 6 & 7 & 13 \\
\hline José Calvo Sotelo & 4 & 9 & 13 \\
\hline General Mola & 5 & 7 & 12 \\
\hline Héroes del Alcázar & 2 & 5 & 7 \\
\hline General Dolla & 0 & 5 & 5 \\
\hline General Miguel Primo de Rivera & 4 & 1 & 5 \\
\hline General Queipo de Llano & 2 & 2 & 4 \\
\hline General Sanjurjo & 1 & 3 & 4 \\
\hline Santiago Cuadrado Suárez & 0 & 4 & 3 \\
\hline General Moscardó & 1 & 2 & 3 \\
\hline General Varela & 1 & 2 & 3 \\
\hline Leopoldo Matos & 2 & 1 & \\
\hline
\end{tabular}

Cuadro 2. Nuevas denominaciones más repetidas en Canarias a partir del 18 de julio de 1936

Elaboración propia. Fuentes: Archivos municipales citados y referencias bibliográficas.

Por otro lado, tal y como sucedió en la Alemania nazi, las personas más conmemoradas en Canarias durante la Guerra Civil fueron el dictador y el «mártir del movimiento» ${ }^{59}$. En efecto, el nombre de José Antonio Primo de Rivera aparecía en 14 de los 33 municipios estudiados. Su nombre fue adjudicado a calles de las distintas poblaciones una vez que las comisiones gestoras tuvieron conocimiento de su fallecimiento. José Antonio, se convertiría en el «caído número uno del régimen ${ }^{60}$, algo que en la práctica se traduciría, por ejemplo, en que él siempre apareciera mencionado en primer lugar en todas las lápidas que recordaban a los caídos y que se colocaban fuera de las iglesias ${ }^{61}$. Aparte de eso, su figura se vincularía a su ausencia, la cual contrastaría con su continua referencia de exaltación y reivindicación en cada uno de los actos públicos y de masas en los que participaban los falangistas, como ocurriría en los de denominación de las calles.

Su caso, al igual que el del general Mola, y otros caídos en el frente de batalla, nos recuerda que los nombres de las calles con fines conmemorativos, tal y como proponen Rose-Redwood, Alderman y Azaryahu, se inscriben en una convención cultural por la que el pronunciamiento de

58 En este sentido cabe destacar la pervivencia de esas denominaciones de militares más allá del franquismo y cómo pervivieron en la mayoría de los casos hasta que fueron eliminados del callejero por la entrada en vigor de la denominada Ley de Memoria Histórica de 2007. En efecto, como evidencia Jesús de Andrés Sanz, el caso de las dos provincias canarias es representativo de la pervivencia de esos nombres asociados a militares, algo que califica como «intensidad alta» y que entronca directamente con el importante número de nombres que pasaron a integrar el callejero de las islas, como se demuestra en nuestro trabajo. Véase, ANDRÉS (2006), p. 25, así como un artículo periodístico en el que se analiza esta situación en una isla no capitalina como es Fuerteventura. VERA, E. (16 de febrero de 2018). "La huella del franquismo se resiste a abandonar el callejero de Fuerteventura». eldiario.es.

Recuperado de https://www.eldiario.es/canariasahora/sociedad/franquismo-resiste-abandonar-callejerofuerteventura_1_2791228.html. [Fecha de la última consulta: 20 de julio de 2020].

59 AZARYAHU (1997), pp. 482-483.

60 THOMAS (2017), p. 405.

61 CASTILLO (2008), pp. 132-149. A modo de ejemplo para el caso de Tenerife, véase BARRERA (1997), pp. 73-74, 76, 78, 79, 83, 86-86, entre otras páginas de este trabajo. 
los nombres propios de los fallecidos facilita su recuerdo ${ }^{62}$. Tal vez, el caso más destacado en el ámbito de la provincia de Santa Cruz de Tenerife fuera el de Santiago Cuadrado, joven falangista asesinado en la Plaza de la Candelaria el 18 de julio de 1936, convirtiéndose en el primer (y único) mártir falangista en territorio insular. Esto motivó desde un primer momento que la Falange iniciara un proceso de exaltación de su figura y que, como decimos, pasado el tiempo, se convirtiera en un hecho inédito en las islas. Tal fue así, que se afirmaría que «ya la Falange Española de la JONS de Santa Cruz de Tenerife tiene un muerto a quien recordar día tras día y un camarada desaparecido de nuestras compactas filas nacional-sindicalistas ${ }^{63}$. No hay otro caído canario que se incorpore tantas veces al viario público, reproduciéndose el recuerdo de aquellos en lápidas ubicadas en el exterior de iglesias o junto a conjuntos monumentales en los que sobresalía una cruz $^{64}$. Pero no era lo único. A esas lápidas se unió también la escenificación del dominio del espacio público, con el desfile de los falangistas, la participación en actos públicos en teatros como el Leal de La Laguna, etc.; todas ellas con el referente a los caídos, algo que en el caso lagunero llevaría a que muchos actos acabaran en el cementerio ante la tumba de Santiago Cuadrado ${ }^{65}$.

Por otro lado, existen otras referencias al fascismo en el viario canario asociadas a aquellas naciones que apoyaron y reconocieron en los primeros momentos al gobierno de Franco, al igual que ocurrió en otros territorios ocupados por los golpistas ${ }^{66}$, y en las que veían un ejemplo a seguir. El 18 de noviembre de 1936 Alemania e Italia reconocieron al gobierno franquista, lo cual generó que propuestas como las que se aprobaron en la ciudad de Las Palmas reafirmaran el compromiso ideológico y de gratitud con los regímenes fascistas. Por su parte, Portugal había suspendido sus relaciones diplomáticas con el Gobierno de la segunda República el 23 de octubre de 1936, si bien el reconocimiento oficial de relaciones diplomáticas y de reconocimiento de iure se produciría el 28 de abril de 1938. No obstante, esas relaciones ya existían desde hacía un año y medio con el gobierno de Burgos y desde amplios sectores sociales se recibiría con satisfacción aquella ruptura de relaciones con el gobierno rojo ${ }^{67}$. En la ciudad de La Laguna (Tenerife), en septiembre de 1936, el secretario judicial Fernando Curbelo Medina solicitaba a los miembros de la Comisión Gestora, dentro de su solicitud, que se le diera el nombre de Portugal a una calle de la población, que ya alguna persona había escrito un rótulo de Calle de Portugal «con pintura muy destacada». En su alocución, añadía que había escuchado comentarios favorables a esta acción, en tanto que Portugal estaba al lado de España «en la lucha de reconquista que contra el marxismo ha emprendido» ${ }^{68}$. Mientras, en la ciudad de Las Palmas, el renombramiento de las calles lleva aparejado una enorme carga ideológica, ya que las calles Italia, Uruguay, Alemania y Portugal sustituirán a las de los referentes socialistas y republicanos Karl Marx, Friedrich Engels, José Nakens y Jean Jaurès ${ }^{69}$. Este segundo grupo de calles representaría un $20 \%$ del total.

El último grupo de calles estaría vinculado con civiles, fechas y lugares vinculados con el Movimiento y representaba menos del 15\% de los renombramientos. En general, no se detecta la incorporación de nombres de las elites políticas al callejero, en tanto que, como se ha dicho, se homenajea a personas muertas o, en su caso, a las figuras militares que participaron activamente en el golpe de Estado o en los primeros combates durante la guerra. En este sentido, destaca la elección del nombre del diputado Calvo Sotelo que respondía a un sentido homenaje a su figura como prócer del proceso de liberación, pero también como una demostración de la victoria sobre sus asesinos, los enemigos de España, los cuales «por bondad y sorpresa del

62 ROSE-REDWOOD, ALDERMAN y AZARYAHU (2010), p. 459.

63 PADRÓN, Hildebrando (30 de julio de 1936). «In memoriam. Santiago Cuadrado Suárez». Gaceta de Tenerife.

64 Para una visión general de las lápidas a los caídos franquistas véase CASTILLO (2008), pp. 132-149.

65 LEÓN (2017), pp. 3589-3599.

66 RINA (2012), pp. 41-42.

67 PENA (2010), pp. 450-460.

68 Archivo Municipal de La Laguna, Sección Protocolo. «Escrito del secretario judicial de La Laguna» (La Laguna, 13 de septiembre de 1936), caja 10.329. En el caso concreto del municipio de La Laguna, se puede consultar LEÓN (2018), pp. 315-336.

69 AHPLP, Ayuntamiento de Las Palmas. «Libro de actas no 94 del Pleno Municipal», fechas 26/08/1936 24/11/1937 (Las Palmas, 2 de octubre de 1936), ff. 25 vto. -26 r. 
pueblo español se encaramaron en el poder, para torcer y esclavizar sus destinos». Estas palabras pertenecían a los actos de celebración por el descubrimiento de la nueva calle de Calvo Sotelo en Teror, donde se reivindicaba su figura y se recordaba que «España a quien él amaba de una manera ejemplar por encima de todas las demás cosas mundanas, se ha redimido y salvado, por lo tanto, era justo que la primera calle que se inaugurara en nuestra isla, llevara el nombre del gran patriota Calvo Sotelo» ${ }^{70}$.

Aparte de su figura, cabe destacar que los nombres de Fernando León y Castillo, Leoncio Bento o Leopoldo Matos recuperarían su presencia en las calles canarias. La reaparición de estas figuras políticas canarias en el viario local significaba, en definitiva, que volvieran a tener importancia destacados hombres de la burguesía canaria de la Restauración y con una participación decisiva en la vida política canaria. Al mismo tiempo, su memoria había sido borrada por las decisiones de las gestoras republicanas, con lo cual se les reintegraba a la vida pública de manera simbólica.

Dicho esto, los únicos casos que se han identificado de figuras políticas locales son los de los gobernadores civiles Antonio García López en Las Palmas y de Julio Fuentes Serrano en Santa Cruz de Tenerife. Respecto a las fechas, tenemos que comentar que el 18 de julio, como efeméride del nacimiento de la "Nueva España" es la tercera calle con más presencia en Canarias, mientras que será anecdótica la utilización de nombres de calles como España o provincia de Navarra.

El predominio de personajes relacionados con la "nación" en vez de con el ámbito local en las vías (re)nombradas durante la Guerra Civil en Canarias está relacionado con la utilización que se hace de los nombres de las calles desde el siglo XIX, y que tiene su culmen en el siglo $\mathrm{XX}$. Los nombres conmemorativos de las calles eran utilizados para construir la nación priorizando a los héroes históricos y a aquellos eventos considerados relevantes por el nacionalismo. Eso influye en ese mayor peso de figuras del ámbito estatal respecto a aquellos otros del local ${ }^{71}$.

\section{PERSONAL POLÍTICO Y CAMBIOS EN EL NOMENCLÁTOR}

El acto de nombrar las calles es una prerrogativa y una expresión de poder de las autoridades designadas $^{72}$. De manera que, coincidiendo con los actos de cambio de denominación de las calles, no solo se estaba procediendo a identificar simbólicamente la vía con el nombre de uno o varios héroes del Movimiento. También se construía un nuevo espacio limitado al partido único, que sustituía lo que hasta entonces había sido punto de encuentro de manifestaciones, protestas o huelgas protagonizadas por las fuerzas políticas y sindicales durante la segunda República. En el caso concreto de la Falange, se trataba de que durante estos actos se conocieran sus verdaderos principios, al tiempo que se llevaba a cabo una demostración de autoridad del régimen naciente ${ }^{73}$.

Durante el descubrimiento del nombre de la calle que se dedicó a Onésimo Redondo en el municipio grancanario de Arucas, la Falange se vio acompañada por la Guardia Civil, las autoridades municipales de la gestora, las organizaciones juveniles y el párroco Silvanio Franco Moreno. Este era el capellán de la Tercera Bandera de Las Palmas y del Campamento Nacional Crucero Baleares y fue el encargado de tomar la palabra durante el acto para recordar al homenajeado y, sobre todo, para pronunciar unas palabras clarificadoras sobre la situación del partido en las islas: «se asombra cuando oye hablar que la Falange es comunista o cosa por el estilo. La Falange no es de izquierdas ni de derechas. La Falange es la entraña de la Patria, que

70 «Teror tiene una nueva calle» (8 de septiembre de 1937). Falange.

71 AZARYAHU (1996), pp. 313-315.

72 AZARYAHU (2011a), pp. 483-484.

73 AZARYAHU (1997), pp. 481-482. «Los desfiles callejeros de las milicias falangistas confluían en multitudinarias manifestaciones de fe religiosa y ardor nacional, donde se fundían las formas sacralizadas del culto católico con los signos de una nueva religión política que exaltaba a la Nación Liberada, y proclamaba el regreso del pasado esplendor imperial y católico de la Patria Única». COBO (2014), p. 29. 
en días aciagos dio el pecho, con el sacrificio de los suyos, contribuyó, la primera, a la salvación de España. Y es profundamente católica».

Aparte de ese proceso de reivindicación de las figuras y emblemas propios, el proceso de definición de las vías públicas llevaba enlazada la destrucción de la herencia republicana, lo cual no solo significaba un cambio de nombres. En ese mismo acto en Arucas, el padre Franco fue muy claro al finalizar su discurso con una frase lapidaria: «En la España actual el que no levanta el brazo estira la pata» ${ }^{74}$.

Junto a la movilización falangista en torno a los actos de descubrimiento de las placas, también se produjo otra católica liderada habitualmente por los párrocos locales. En el caso del municipio de Santa Brígida, en el centro de Gran Canaria, el cambio de denominación de varias de sus calles (Franco, José Antonio Primo de Rivera. José Calvo Sotelo, Defensores del Alcázar y 18 de Julio) se hizo coincidir con la primera comunión de los niños y niñas inscritos en las escuelas nacionales, al que se unió la procesión del niño Jesús de la parroquia, la participación de las autoridades civiles y milicias de Falange ${ }^{75}$.

La consulta de las actas de las comisiones gestoras nos ha permitido detectar que tanto los intereses personales como las experiencias individuales influyeron notablemente en el activismo simbólico de algunos gestores: en muchos casos, por su vinculación ideológica con la Falange desde meses antes al golpe de Estado, pero sobre todo por las experiencias generadas antes, durante y después de la propia guerra, que actuaría como definidora de emociones y comportamientos que, vinculados al proceso político, favorecerían la modificación del espacio público $^{76}$.

El predominio de hombres procedentes de los partidos políticos conservadores y de la etapa de la dictadura de Primo de Rivera fue clave durante estos primeros años y su presencia era una demostración del complejo proceso de institucionalización del nuevo régimen y, por ende, del propio partido ${ }^{77}$. En ese sentido, habría que tener en cuenta que su influencia en el cambio de denominación de las calles no fue tan determinante como sí lo había sido la presencia de destacados falangistas locales o, en su caso, de hombres que habían dado a sus hijos para lograr la liberación de la patria. En los casos de quienes procedían de las etapas anteriores, se podría valorar como un acatamiento de la disposición militar en cuanto a la eliminación del pasado republicano y de exaltación de los nuevos referentes políticos de España, mientras que en el de los segundos habría que valorar su relación ideológica, pero también emocional y de reivindicación de una memoria perpetua en piedra y en el lenguaje cotidiano del vecindario de quienes habían hecho posible la paz.

Las personas que defendieron el cambio de nombres de las calles en sus municipios lo hicieron fundamentalmente por cuestiones ideológicas, pero también es cierto que una propuesta de este tipo era motivo suficiente para realzar su adhesión y lealtad al régimen naciente. Podemos poner como ejemplo al presidente de la Comisión Gestora de Moya, un militar que impulsó el primer cambio en el callejero de la provincia de Las Palmas a fines de agosto de

74 Las frases entrecomilladas de este párrafo y del anterior pertenecen a «Mirador azul de las Islas. De Arucas» (27 de julio de 1939). Falange.

75 «En Santa Brígida» (15 de mayo de 1937). Falange.

En el caso de Teror, municipio en el que se encuentra la patrona de la isla, se viviría una situación similar, nuevamente con la presencia del párroco local que tuvo un papel destacado en los actos, participando activamente con su discurso en el descubrimiento del nombre de Generalísimo Franco a la principal vía de comunicación y con una pequeña conferencia sobre el Movimiento y sus principales líderes. «Mirador azul de las Islas. De Teror» (21 de julio de 1937). Falange.

76 En Güímar se produjo un hecho nada habitual en las islas durante esos momentos. El 12 de agosto de 1936 el alcalde Juan Chávez Cejas y su gestora procedieron a retirar los nombres de las calles dedicadas, durante la segunda República, a Francisco Ferrer i Guardia y a Luis del Sirval. En ese sentido, el alcalde argumentaba tal decisión diciendo que «el Ayuntamiento socialista anterior que precedió a esta Gestora, por afán de imitación gregaria, por snobismo pueril, sin otro sentido, significación ni finalidad que dejar huella de su sectarismo rabioso y herir los sentimientos españolistas de la mayoría de este pueblo». AMG: «Libro de actas de 1936» (Güímar, 12 de agosto de 1936), Libro 1728/2.

77 Para la provincia oriental, véase el estudio sobre el Cabildo de Gran Canaria de ALCARAZ (1999), pp. $97-$ 114. En el caso de la provincia occidental, aparte de los cuatro cabildos insulares, también se analizan los municipios de mayor peso económico y poblacional, así como las delegaciones del Gobierno. LEÓN (2016) pp. 121-163. 
1936. Con esta iniciativa seguro que quería ganar el favor de las autoridades civiles y militares radicadas en la capital provincial. Poco después de ese hecho tuvo que renunciar a su cargo en noviembre de 1936, por haber sido designado por la Comandancia Militar de Las Palmas para servir en un puesto de mando en la guarnición ${ }^{78}$.

Sin embargo, es en las capitales provinciales donde se produce el mayor número de acuerdos al respecto y donde podemos observar de una forma más detallada las distintas acciones individuales. Tomando como ejemplo el caso de la comisión gestora del Ayuntamiento de Las Palmas, nos encontramos con dos casos de gestores que formaron parte de ella durante la Guerra Civil y que tuvieron un papel preeminente en ese proceso, al menos por tener iniciativas concretas y con un profundo matiz ideológico y político ${ }^{79}$.

Antonio Grondona y Martín Fernández pertenecía a una familia con una dilatada trayectoria comercial en la ciudad y eran precisamente las raíces de sus antepasados las que le asociarían a Italia. Esos vínculos los mantendría el mencionado gestor por su profesión de comerciante (entre otras cosas, era importador de licores y alcohol y propietario de un comercio en la ciudad) y por sus frecuentes viajes a ese país, al que, más allá de lo familiar, mostraba una profunda admiración y relación con el régimen fascista de Mussolini. Durante su breve período como gestor (31 de mayo de 1937 - 9 de septiembre de 1937) defendió, desde la primera sesión a la que asistió, el que se estudiara dar los nombres de Hitler y Mussolini a calles o plazas de las más importantes de la ciudad, cuestión que quería que se comunicase a los cónsules de Alemania e Italia residentes en Las Palmas ${ }^{80}$. En sucesivas sesiones propondrá y defenderá este proyecto ante sus compañeros, así como el homenajear mediante el mismo procedimiento al general Primo de Rivera, a Calvo Sotelo y al general Mola. En julio de 1937 viaja a Italia en representación de la Corporación Municipal para estudiar una serie de problemas que preocupaba a los gestores, así como «cuantos servicios requieran orientación y medios completamente modernos» ${ }^{81}$. Recibió el apoyo del embajador español para poder llevar hasta Gran Canaria unas películas patrocinadas por el Ministerio de Propaganda italiano que se exhibieron en el Hollywood Cinema capitalino en noviembre de 1937, para homenajear a Italia y Alemania con motivo del reconocimiento «del gobierno de la España auténtica» ${ }^{82}$. Este acto, al que asistieron las autoridades locales e insulares de FET y de las JONS, también contó con la presencia de los cónsules de ambos países ${ }^{83}$, reafirmando así el compromiso de Antonio Grondona con los regímenes fascista y nazi. Sus intereses profesionales e ideológicos iban de la mano en su labor como gestor municipal, con especial empeño en otorgar calles a los líderes nazi y fascista, cuestión a la que no accedieron el resto de compañeros.

En la configuración del callejero de la capital grancanaria también debe tenerse en cuenta el perfil de Silvestre Bello Rodríguez, destacado hombre de la sociedad local por su labor como médico de la ciudad, jefe local de la Falange, y que formó parte de la Comisión Gestora desde su constitución en el verano de 1936 hasta 1938. Llegó a ocupar el cargo de primer teniente de alcalde y, en ocasiones, las de alcalde accidental, entre otros cargos. Se trataba de un ferviente católico, miembro de la Cofradía del Santísimo Cristo del Buen Fin, y con una amplia trayectoria en el entramado asociativo de Las Palmas, formando parte, entre otras, de la Real Sociedad Económica de Amigos del País, del Colegio Oficial de Médicos y del Gabinete Literario. La muerte de su hijo Rafael Bello del Toro, un joven falangista que había partido a la Guerra Civil como parte de las centurias expedicionarias de Falange Canaria en el frente sur, tras el bombardeo del hospital de Córdoba a comienzos de abril de 1937, será crucial en su

78 AHPLP, Ayuntamiento de Moya: «Libro de actas de 1936» (Moya, 13 de noviembre de 1936), ff. 148 r. 149 vto.

79 En el caso de Bilbao, por ejemplo, la llegada a la alcaldía de José María de Areilza significó la introducción de «cambios mucho más radicales» que en las otras dos provincias vascas. La historiadora Virginia López de Maturana lo relaciona con toda la trayectoria política de Areilza, algo que explicaría la intensa acción conmemorativa que desarrolló durante su mandato. LÓPEZ DE MATURANA (2015), pp. 90-91.

80 AHPLP, Ayuntamiento de Las Palmas: «Libro de actas n 94 del Pleno Municipal, fechas 26/08/1936 24/11/1937» (Las Palmas, 9 de junio de 1937), f. 159 r.

81 AHPLP, Ayuntamiento de Las Palmas: «Libro de actas n 94 del Pleno Municipal, fechas 26/08/1936 24/11/1937» (Las Palmas, 2 de julio de 1937), f. 172 r.

82 «Función homenaje a Italia y Alemania» (19 de noviembre de 1937). Falange.

83 «Función homenaje a Italia y Alemania» (19 de noviembre de 1937). Falange. 
actividad en la vida política municipal. A partir de aquel trágico acontecimiento, unido a su ferviente catolicismo y su activa colaboración con los voluntarios desplazados a la Península, se convertirá en un destacado defensor del cambio de los nombres de las calles de Las Palmas para honrar a los héroes de la misma, como es el caso del Cabo de Infantería Antonio Alemán Rodríguez, quien sería el primer canario laureado con la Cruz Laureada de San Fernando por méritos de guerra ${ }^{84}$, o de los caídos durante la contienda bélica, ya fueran altos cargos militares o heroicos falangistas. Así podemos observar como en ocasiones los factores individuales fueron importantes, si bien no se entendería su importancia sin atender, como hemos planteado en páginas anteriores, a un proceso colectivo de renombramiento de las calles en el marco de la Guerra Civil.

Por último, no podemos olvidar el trabajo realizado por el cronista de Las Palmas Carlos Navarro Ruíz, que será publicado entre 1940 y $1943^{85}$. Navarro Ruíz fue concejal del Ayuntamiento de Las Palmas entre 1912 y 1916, momento en el que pretende que la Biblioteca Municipal realice un estudio sobre los nombres de las calles de la ciudad, para una mejor administración de Las Palmas. Debido a que este trabajo nunca fue acometido, será realizado por Navarro en calidad de Cronista y bajo encargo del Ayuntamiento. El fin de la obra será dar a conocer la biografía de los nombres conservados, aclarar aquellos que generan confusión y realizar nuevas propuestas que tendrán que ser corroboradas por el Ayuntamiento durante la década de 1940, una vez acabada la Guerra Civil ${ }^{86}$.

\section{CONCLUSIONES}

La reconfiguración del espacio público se desarrolló en los primeros meses que siguieron al golpe de Estado de 18 de julio de 1936. Ese hecho se enmarca en ese proceso histórico que se abrió a partir de entonces y que se concretó en la definición de un viario público, al cual, tal como se ha explicado en páginas anteriores, se trasladó el poder de los militares vencedores, sus caídos y mártires, así como cualquier otro referente que los vinculara con su idea de España. Todo ha sido explicado en las páginas anteriores a partir de la perspectiva teórica de los critical place-name studies que nos ha permitido sustentar teóricamente un proceso histórico que ha ido más allá del ámbito geográfico español y canario y, por supuesto, del propio franquismo. En todo caso, a lo largo de este artículo hemos demostrado, a partir de un muestreo representativo de municipios canarios, que los integrantes de las comisiones gestoras canarias introdujeron la concepción del régimen en el nomenclátor de las vías de sus municipios a través de personas, fechas y lugares vinculados con el nuevo poder emergente y su participación en la Guerra Civil. Entre ellas, destacan las denominaciones tradicionales vinculadas con la religión católica y los nombres de los militares de ámbito nacional del bando sublevado. En especial, el general Franco, quien había partido desde Canarias, y sería la figura más nombrada, también en aquellos lugares más importantes en cuanto a tránsito y sociabilidad de cada localidad. Se ponía pues en marcha la construcción de una memoria colectiva durante el período bélico, siendo los territorios de retaguardia como Canarias la base sobre la que se construyó y que, a su vez, ponen en primer plano su importancia para entender los orígenes de la dictadura y el discurso imperante a partir del 1 de abril de 1939 con el final de la guerra.

La realización de estudios desde el ámbito local y regional permitirán conocer las diferencias y semejanzas de este proceso en los distintos contextos que se dieron durante la contienda bélica. De esa manera, se creará un conocimiento empírico, alejado de ideas genéricas y que contribuirá a conocer cómo se desarrolló ese proceso en distintos territorios. Por último, la investigación de los símbolos y la memoria del franquismo, tal y como los conceptualizó Jesús de Andrés, permitirá realizar propuestas sólidas a las administraciones públicas para el

84 «Como ganó el hijo de Gran Canaria Antonio Alemán Ramírez la Laureada de San Fernando» (27 de junio de 1938). Falange.

85 NAVARRO (1940 y 1943).

86 NAVARRO (1940), pp. V-VII, 241-244. 
cumplimiento de la Ley de Memoria Histórica, como las realizadas por este autor a nivel general o por Aitor González y Virginia López para el País Vasco ${ }^{87}$, entre otras.

\section{REFERENCIAS}

AGUILAR FERNÁNDEZ, Paloma (2008). Políticas de la memoria y memorias de la política: el caso español en perspectiva comparada. Madrid: Alianza Editorial.

ALCARAZ ABELLÁN, J. (1999). Instituciones y sociedad en Gran Canaria 1936-1960. Madrid: Cabildo de Gran Canaria.

ALDERMAN, D. H. (2003). «Street names and the scaling of memory: the politics of commemorating Martin Luther King, Jr within the African American community». Area, núm. 35 (2), pp. 163-173.

ALDERMAN, D. H. e INWOOD, J. (2013). «Street naming and the politics of belonging: spatial injustices in the toponymic commemoration of Martin Luther King Jr». Social \& Cultural Geography, núm. 14 (2), pp. 211-233.

ANDRÉS SANZ, J. de. (2006). Los símbolos y la memoria del franquismo. Madrid: Fundación Alternativas.

AZARYAHU, M. (1986). «Street Names and Political Identity: The Case of East Berlin». Journal of Contemporary History, núm. 21 (4), pp. 581-604.

AZARYAHU, M. (1996). «The power of commemorative street names». Environment and Planning D: Society and Space, núm. 14, pp. 311-312.

AZARYAHU, M. (1997). «German reunification and the politics of street names: the case of East Berlin». Political Geography, núm. 16 (6), pp. 479-493.

AZARYAHU, M. (2011a). «The politics of commemorative street renaming: Berlin 19451948». Journal of Historical Geography, núm. 37, pp. 483-492.

AZARYAHU, M. (2011b). "The critical turn and beyond: the case of commemorative Street naming». ACME: An International E-Journal for Critical Geographies, núm. 10 (1), pp. 28-33.

AZARYAHU, M. (2012). «Hebrew, Arabic, English: the politics of multilingual street signs in Israeli cities». Social \& Cultural Geography, núm. 13 (5), p. 461.

BARRERA TRUJILlO, A. L. (1997). Monumentos a los Caidos de la Guerra Civil Española, en la isla de Tenerife (Memoria de licenciatura). Universidad de La Laguna (Facultad de Bellas Artes), La Laguna.

BERNECKER, W. L. y BRINKMANN, S. (2009). Memorias divididas. Guerra civil y franquismo en la sociedad y la política españolas, 1936-2008. Madrid: Abada editores, 2009.

BIGON, L. y NJOH, A. J. (2015). «The Toponymic Inscription Problematic in Urban SubSaharan Africa: From Colonial to Postcolonial Times». Journal of Asian and African Studies, núm. 50 (1), pp. 25-40.

BOX, Z. (2010). España, año cero. La construcción simbólica del franquismo. Madrid: Alianza.

CASTRO, L. (2008). Héroes y caídos: políticas de la memoria en la España contemporánea. Madrid: Los Libros de la Catarata.

COBO ROMERO, F. (2014). «Acerca de los iniciales apoyos sociales prestados al franquismo. La mitificación de la Guerra Civil y la vivencia alegórica de la contienda en la retaguardia rebelde». En LEÓN ÁLVAREZ, A. (coor.), El Franquismo en Canarias. Actas del Encuentro de Historia sobre el franquismo en Canarias. Santa Cruz de Tenerife: Le Canarien Ediciones-Instituto de Estudios Canarios, pp. 19-49.

COHEN, S. B. y KLIOT, N. (1992). «Place-Names in Israel's Ideological Struggle over the Administered Territories». Annals of the Association of American Geographers, núm. 82 (4), pp. 653-680.

87 ANDRÉS (2006), GONZÁLEZ DE LANGARICA y LÓPEZ DE MATURANA (2013); LÓPEZ DE MATURANA (2014 y 2015). 
CASTILLO GÓMEZ, A. (2008). «Escritura, monumento y memoria: las lápidas a los caídos franquistas». Cultura Escrita \& Sociedad, núm. 6, pp. 132-149.

DROZDZEWSKI, D. (2014). «Using history in the streetscape to affirm geopolitics of memory». Political Geography, núm. 42, pp. 66-78.

DUMINY, J. (2014). «Street renaming, symbolic capital, and resistance in Durban, South Africa». Environment and Planning D: Society and Space, núm. 32, pp. 310-328.

GODICHEAU, F. y ARÓSTEGUI, J. (2006). Guerra Civil: mito y memoria. Madrid: Marcial Pons.

GARCÍA LÁZARO, N. (2011). «La ciudad etiquetada. Los casos de La Laguna y Santa Cruz de Tenerife». En R. J. GONZÁLEZ ZALACAIN, B. DIVASSÓN MENDÍVIL y J. SOLER SEGURA, Actas de las IV Jornadas Prebendado Pacheco de Investigación Histórica. Ayuntamiento de Tegueste, pp. 281-308.

GONZÁLEZ DE LANGARICA, A. y LÓPEZ DE MATURANA, V. (2013). Catálogo de símbolos y monumentos existentes en Euskadi que supongan una exaltación de la Guerra Civil y la Dictadura. Vitoria-Gasteiz: Gobierno Vasco.

GRABAR, H. S. (2014). «Reclaiming the city: changing urban meaning in Algiers after 1962». Cultural geographies, núm. 21 (3), pp. 389-409.

GRETAN, R. y MATTHEW, P. W. (2016). «Popular responses to city-text changes: street naming and the politics of practicality in a post-socialist martyr city». Area, núm. 48 (1), pp. 92-102.

HALBWACHS, M. (2002). «Fragmentos de la Memoria Colectiva». Athenea Digital: revista de pensamiento e investigación social, núm. 2, pp. 103-113.

HENALES SALAMANCA, J. (2019). «El callejero de Alicante durante la guerra civil española: 1936-1939», Ebre, núm. 38, pp. 111-130.

LEÓN ÁlVAREZ, A. (2016). La retaguardia de Franco. Poder local y personal politico en las Canarias Occidentales, 1936-1961. Santa Cruz de Tenerife: Instituto de Estudios Canarios.

LEÓN ÁlVAREZ, A. (2017). «Los mártires del falangismo canario: entre el frente de guerra, la retaguardia y las instituciones». En D. A. GONZÁLEZ MADRID, M. ORTIZ HERAS, y J. S. PÉREZ GARZÓN (eds.), La Historia, lost in translation?: Actas del XIII Congreso de la Asociación de Historia Contemporánea, celebrado en Albacete del 21 al 23 de septiembre de 2016. Cuenca: Ediciones de la Universidad de Castilla-La Mancha, pp. 3589-3599.

LEÓN ÁLVAREZ, A. (2018). «El espacio público de La Laguna: del conflicto histórico (1931-1939) al reciente combate por la memoria». En R. J. GONZÁLEZ ZALACAÍN y C. RODRÍGUEZ MORALES (coors.), Los patrimonios de La Laguna. La Laguna: Instituto de Estudios Canarios, pp. 315-344.

D. LIGHT, y C. YOUNG (2014). «Habit, Memory, and the Persistence of Socialist-Era Street Names in Postsocialist Bucharest, Romania». Annals of the Association of American Geographers, núm. 104 (3), pp. 668-685.

LÓPEZ DE MATURANA, V. (2014). La reinvención de una ciudad. Poder y política simbólica en Vitoria durante el franquismo (1936-1975). Bilbao: Servicio Editorial de la Universidad del País Vasco.

LÓPEZ DE MATURANA, V. (2015). «Huellas de un pasado dictatorial. La pervivencia del nomenclátor franquista en las calles del País Vasco». Intus-Legere Historia, núm. 2, vol. 9, pp. 85-98.

MARIN, A. (2012). «Bordering Time in the Cityscape. Toponymic Changes as Temporal Boundary-Making: Street Renaming in Leningrad/St. Petersburg». Geopolitics, núm. 17 (1), pp. 192-216.

MEITAL, Y. (2007). «Central Cairo: Street Naming and the Struggle over Historical Representation». Middle Eastern Studies, núm. 43 (6), p. 857-878.

NAVARRO RUIZ, C. (1940). Nomenclátor de calles y plazas de Las Palmas. Las Palmas de Gran Canaria: Tip. Diario. Tomo I.

NAVARRO RUIZ, C. (1943). Nomenclátor de calles y plazas de la ciudad de Las Palmas de Gran Canaria. Las Palmas de Gran Canaria: Tip. Diario. Tomo II. 
PENA RODRIGUES, A. (2010). «Portugal, España y la historia del Estado Novo: las Relaciones Ibéricas y los medios de comunicación salazaristas en los años treinta». En M. M. TAVARES RIBEIRO (coor.), Outros combates pela história. Coimbra: Universidad de Coimbra, 2010, pp. 450-460.

PLATERO FERNÁNDEZ, C. (1998). Calles de Las Palmas. Las Palmas de Gran Canaria: Ediciones del Cabildo Insular de Gran Canaria.

RAMÍREZ SÁNCHEZ, M. (2016). Historias en la piedra. La escritura última en los cementerios ingleses de Canarias. Madrid: Dykinson.

RINA SIMÓN, C. (2012). «El dominio simbólico del espacio urbano: La construcción del franquismo en Cáceres». Transitions: Journal of Franco-Iberian studies, núm. 8, pp. 35-55.

RINA SIMÓN, C. (2013). «Las 'guerras de la memoria' entre militares y falangistas en Cáceres, 1936-1942». En M. Á. RUIZ CARNICER(ed.), Falange, las culturas políticas del fascismo en la España de Franco (1936-1975), vol. 2. Zaragoza: Institución "Fernando el Católico", pp. 444-462.

RODRÍGUEZ DELGADO, O. (2 de junio de 2015). Distinciones municipales y nominaciones oficiales concedidas por el Ayuntamiento de Fasnia hasta la Guerra Civil (1900-1939). Recuperado de http://blog.octaviordelgado.es/distinciones-municipales-ynominaciones-oficiales-concedidas-por-el-ayuntamiento-de-fasnia-hasta-la-guerracivil-1900-1939/. [14 de abril de 2020].

ROSE-REDWOOD, R., ALDERMAN, D. y AZARYAHU, M. (2010). «Geographies of toponymic inscription: new directions in critical place-name studies". Progress in Human Geography, núm. 34 (4), pp. 453-470.

SÁNCHEZ COSTA, F. (2009). «Cultura histórica y nombres de calles. Aproximación al nomenclátor contemporáneo de Barcelona y Madrid». Memoria y Civilización ( $M \& C$ ), núm. 12, pp. 217-251.

SEVILLANO CALERO, F. (2017). La cultura de guerra del "nuevo Estado" franquista. Enemigos, héroes y caídos de España. Madrid: Biblioteca Nueva.

SUBIRANA, Jaume (2017). «A present past, Barcelona Street names, from Víctor Balaguer to Pasqual Maragall». En E. BOU, y J. SUBIRANA (Eds.), The Barcelona Reader: Cultural Reading of a City. Liverpool: Liverpool University Press, pp. 71-90.

THOMAS, J. M. (2017). José Antonio. Realidad y mito. Barcelona: Debate.

WANJIRU, M. W. y MATSUBARA, K. (2017). «Street toponymy and the decolonisation of the urban landscape in post-colonial Nairobi». Journal of Cultural Geography, núm. 34 (1), pp. 1-23. 